\title{
Application of loT Concepts for Home Security Systems
}

\author{
Ali A.S. Ramschie \\ Department of Computer \\ Engineering \\ Manado State Polytechnic
}

\author{
Johan F. Makal \\ Department of Electrical \\ Engineering \\ Manado State Polytechnic
}

\author{
Veny V. Ponggawa \\ Department of Computer \\ Engineering \\ Manado State Polytechnic
}

\author{
Ronny Katuuk \\ Department of Electrical Engineering \\ Manado State Polytechnic
}

\begin{abstract}
The security factor of residential homes today has become a necessity, especially the use of monitoring cameras (CCTV) which function as a medium for monitoring activities that occur at home, when left uninhabited.

This study aims to create a system that can document activities that occur in residential rooms through the application of the IoT concept. The system created is equipped with a Passive Infra Red sensor which is used to detect people in the room and automatically activates the alarm and camera to take pictures when someone is indicated to be in the room, and will send image data taken to the web server and notifications to homeowners via Android Smartphones. so that wherever the owner of the house is, he can know if someone has entered his house.

The test results show that the system can carry out the process of securing the room, through detecting the movement of people in the room. If the PIR sensor detects someone in the room, the system will automatically activate the alarm, take 5 pictures and send the captured image to the web server as monitoring data, and send notifications to homeowners via Smartphone devices. The data stored on the web server can be printed in pdf format as monitoring data or reporting data.
\end{abstract}

\section{Keywords}

CCTV, IoT, Home Securyty, Pir.

\section{INTRODUCTION}

The application of a security system in residential homes through the use of CCTV [1] is an effort from homeowners to get a sense of security, when the house is left uninhabited. In principle, the CCTV system commonly used today is to use a camera device as a monitoring medium, which is connected to a PC device that functions as a storage medium and monitoring the monitoring results from the camera. The weakness in this system is in terms of monitoring the stored recordings, where to see the recording results from this CCTV system, the user must play the entire contents of the recordings stored on the PC device. Another thing that affects the weakness of this security system is in terms of the storage area for recording the results, where when the storage area is full, the system can no longer carry out the recording process, and if a crime occurs when the storage media is full, the monitoring process will not be carried out. will be saved.

To overcome this problem, the author makes a residential security system using an IoT-based ESP32 controller [2][3]. Where the system made is equipped with a Passive Infra Red
(PIR) sensor which is used to detect people in the room [4][5]. If it is detected that someone has entered the room when the security system is activated, the system will automatically activate the alarm that is installed adjacent to the camera, so that people who enter will look for the source of the sound produced, and the camera will process the image and data results. The shooting will be sent to the web server, and the system will send a notification to the homeowner that someone has entered the room through the Android application [6] which is embedded in the Android Smartphone, so that wherever the homeowner is located, he or she can find out if someone has entered the room. enter his house. Homeowners can report to related parties if it is indicated that there has been a theft with evidence in the form of taking pictures of people who enter the house that was successfully captured by the camera, and this stored image data can be downloaded from the web server, complete with the time of the incident.

Similar studies that have been carried out include implementing IP camera routing to monitor laboratory rooms and designing IP camera technology in wireless radio networks, both of which still use desktop devices [7][8]. Furthermore, research on the design of a room monitoring application via an IP camera using the Android platform, the results are able to perform live streaming without burdening the memory of the Android device, but require a large bandwidth to be able to display the full movement of objects, but in this design the user must monitor the condition continuously. or save video data from ip camera periodically [9]. Then the next research is the design of a wifi-based environmental security monitoring system using an IP camera, the results can be accessed on the Android mini PC screen by controlling the IP camera and motion detection using a webbased IP camera [10][11].

\section{METHODOLOGI}

In producing an IoT-based residential security system, it refers to the Prototyping research method, where the stages include data collection, hardware design, software design, system testing to obtain data related to system work in the home security process.

\subsection{System Design}

In hardware design, it is necessary to have an overview of the system that will be made later to make it easier for the author in making the system. The description of the system to be made is in the form of a block diagram of the entire system. Figure 1 shows a block diagram of the control system created. 


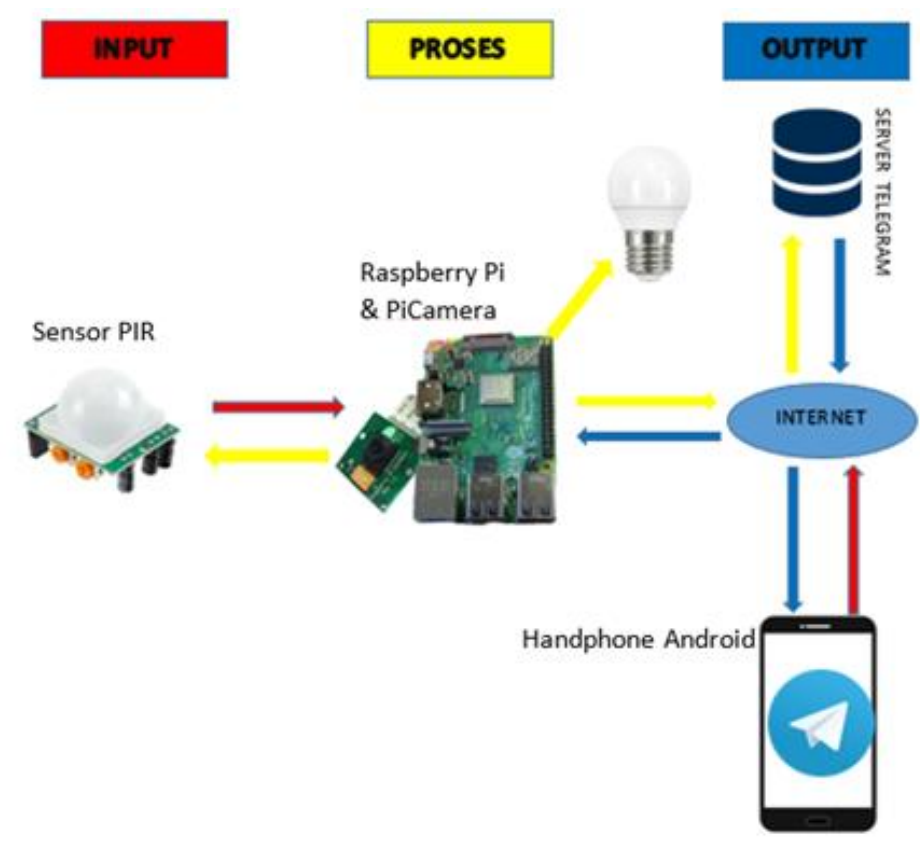

Fig 1: Block diagram system

The description of the Block diagram in Figure 1, is described as follows:

1. Smartphone, serves as a monitoring medium via remote to monitor the condition of the house if someone is detected entering, via a web browser.

2. Wifi module, functions as a communication medium between the web server and controller for the process of sending captured data when there is an indication of movement in the room.

3. Controller, functions as a data processing center and controller, for security system needs.

4. Passive Infra Red Sensor, serves as a medium for detecting movement in the room based on human body temperature.

5. The web cam functions as a medium for taking pictures, when there is an indication of movement in the room.

6. Buzzer functions (Lamp) as an alarm when there is an indication of movement in the room.

7. The web address serves as a media for storing data captured from the nodeMCU controller when there is an indication of movement in the room, besides that the web also functions as a monitoring medium for the state of the department or room whether there are people who enter or not. At the web address, it is also possible to print files in pdf format, for image data when it is indicated that someone has entered.

\subsection{Flowchart System (Algorithm)}

Software design is needed to describe the program workflow to match the program needs of the residential security system that will be made. The design of this software includes 3 parts consisting of:

\subsubsection{Flow chart System (Algorithm)}

Software design for system work control needs in the form of flowcharts that function to control system work, in terms of conducting room monitoring processes, in connection with home security. The work control flowchart of the system is shown in Figure 2.

The working order of the flow chart is as follows:

When the system is first run, the system will perform the system setup and Wifi synchronization process as well as the web address that acts as an intermediary for communication between the web server and the controller. After the synchronization process is complete, the system will detect whether there is movement in the room through the PIR sensor. If the PIR sensor does not detect any movement in the room, then the PIR sensor reading process will continue. If the PIR sensor detects movement in the room, the system will activate the web cam to take pictures, and the image data will be sent to the web server. The next step is to read the number of pictures taken, whether there are 5 pictures or not. If the number of pictures taken has not been 5 pictures, the system will continue to activate the web cam to take pictures and send them to the web server. If there are 5 pictures taken, the system will disable the working of the web cam, then the system will enter the program section to read the PIR sensor. This process will continue, until the system is disabled. 


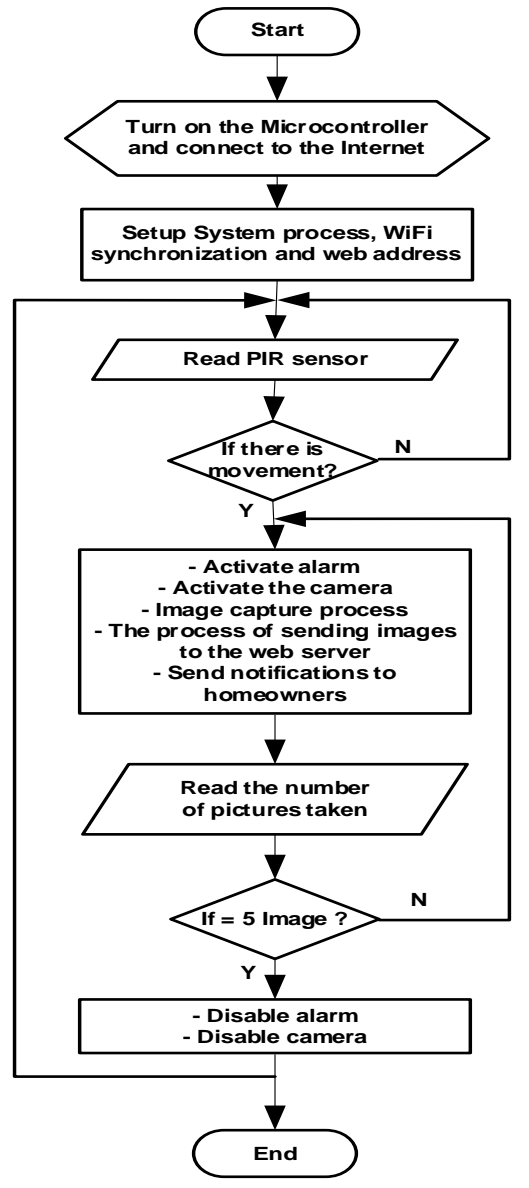

Fig 2:Flowchart system

\subsubsection{Web Server Design}

In the web design section, it is carried out based on the needs of the system to be created. The design of this web display aims to store images captured on a home security system, as well as a medium of communication between the controller device and the monitoring system, which in this case is a smartphone device. Figure 3 shows the created web view.

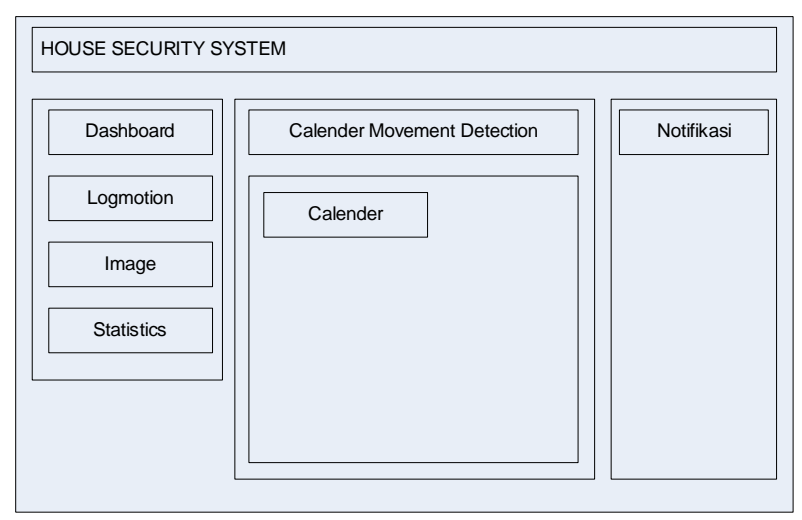

Fig 3:Dashboard WebServer

Next is the design of the form for the section to display the results of the image storage process that is sent through the controller, as a result of taking pictures when it is indicated that someone is in the room, as shown in Figure 4.



Fig 4:Dashboard Web Server

\subsection{Home Security System Manufacturing}

The process of making a home security system is carried out based on the design results that have been produced through the system design process (system block diagram), where the stages of manufacture are as follows:

\subsubsection{Hardware Manufacturing}

The manufacture of hardware is carried out by referring to the results of the hardware design in the form of block diagrams. Hardware manufacturing is done by combining modules such as: PIR sensor module, Buzzer module and camera and controller module, so that they are integrated with each other. Figure 5. shows the results of making hardware.

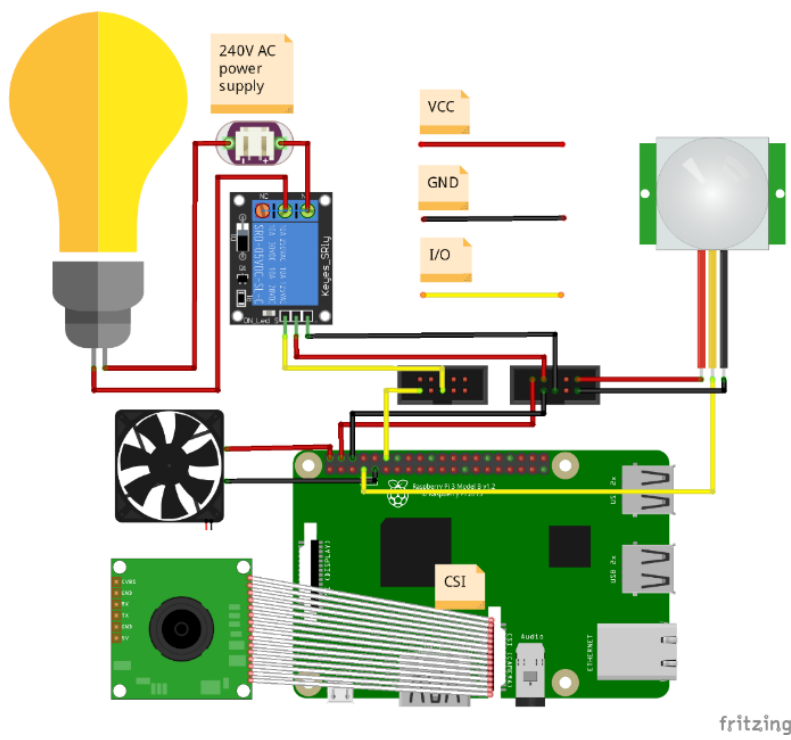

Fig5:Simulation Sistems

After producing the integrated hardware, the next step is the packaging process. The results after the packaging process are shown in Figure 6.



Fig6:The packaging process 


\subsubsection{Software Development For Controller Operations}

Making software for the work needs of controlling the of the system which will be embedded into the controller is made based on the results of the software design, with reference to the stages of the algorithm in accordance with the flowchart made. The process of making software for system work operations using the Arduino IDE as shown in Figure 7.

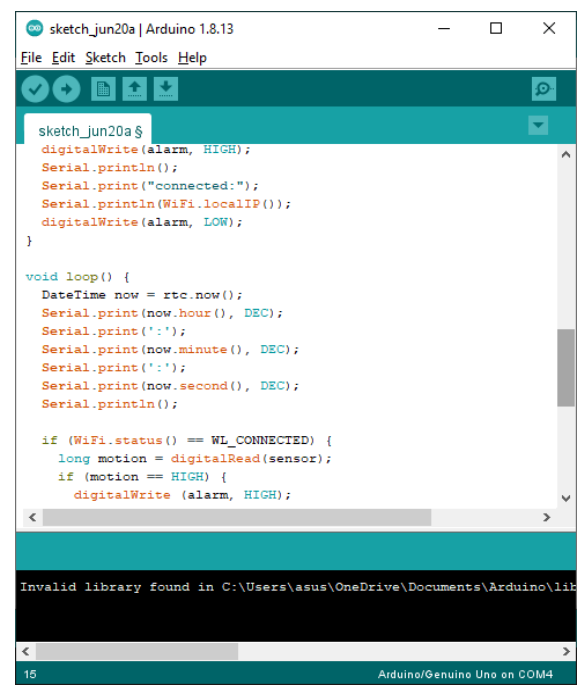

Fig7:Software Development for controller

\subsubsection{Development For Server Web}

The web creation is done using the PHP my Admin software, where the web created functions as a medium for storing image data sent from the controller via wifi communication, when it is indicated that someone is entering the room. The web display created is shown in Figure 8.



Fig8:Server Web Development

\subsubsection{Android Apk Build}

The stages in making Android applications refer to the results of the design, where the process of making Android applications is carried out through the makeroid application. Where on Android this application functions as a media for receiving notifications from the web server, when it is indicated that someone has entered the house. Besides that, this Android application is also made as a replica of the web server, so that users can see the recording results stored on the web server when it is indicated that someone has entered the house. Making Android applications is shown in Figure 9.



\section{RESULT AND DISCUSSION}

System work testing is done by integrating each module to form a unified system. System integration includes a controller module that has been integrated with a PIR sensor module, and a buzzer that functions as an alarm, a wifi module as a communication medium between the controller and the web server and a web cam module as a medium for taking pictures when someone is indicated to enter the room. Figure 10 shows the Security system created.

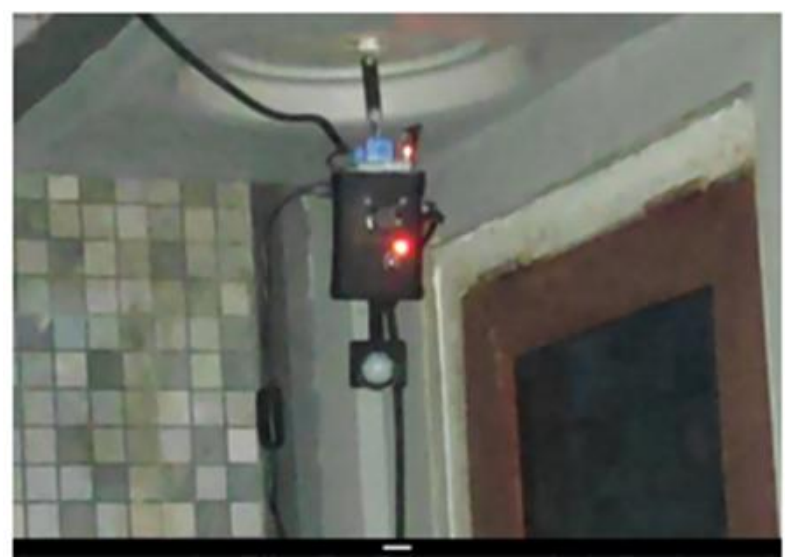

Fig10:IoT Based Home Security System Testing

The working principle of the system is as follows:

1. Detect object movement, When the system is activated, the system will carry out the process of securing the residence by detecting the movement of human objects in the room through the PIR sensor. The part of the program to read the state of the PIR sensor is as follows:

$$
\begin{aligned}
& \text { if (Wifi.status }()==\text { WL_CONNECTED) }\{ \\
& \text { HTTPClient http; } \\
& \text { long motion = digitalRead(sensor); }
\end{aligned}
$$

When the sensor detects motion, as shown in Figure 11, the sensor will input HIGH logic to the controller, then the controller will process the data to activate the web cam for image capture and send the captured image data to the web server via wifi communication. 




Fig11:Information when the PIR sensor detects human movement

The part of the program that is run when the PIR sensor detects human movement is as follows:

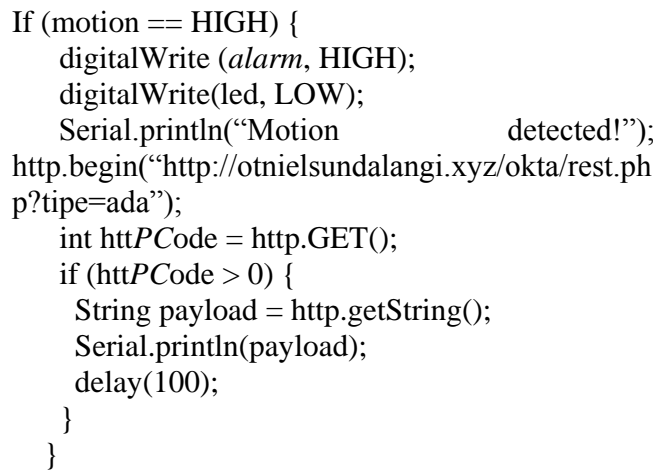

After the data is sent and received by the web server, the notification section on the web server will contain information about the incoming image data. Image data taken and sent to the web server is limited to only 5 images. If no movement is detected, the system will deactivate the work of the web cam and disconnect the wifi, so that the web cam does not work continuously to perform the recording process, thus extending the operating life of the web cam. Data storage can also be minimized because only 5 image data is sent to the web server.

When the notification is received by the user through his smart phone device, the user will be directed to the web server to view the monitoring results stored on the web server. Figure 12 shows the web server display as a dashboard to view data recorded by the residential security system.

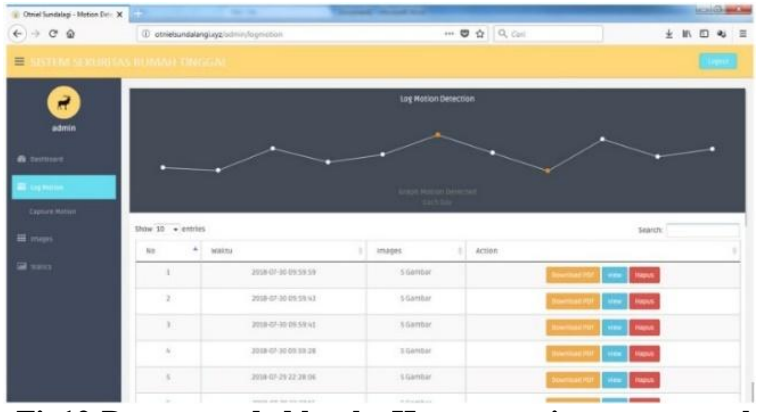

Fig12:Data recorded by the Home security system on the web server

In the Web server display section to view the recorded data from the residential security system, users can print the recording results in pdf format, monitor the stored image recordings and delete the data recorded from the residential security system.

If the user chooses to view the saved image data, then what can be done is to press the View button. When the View button is pressed, the system will direct and open a section/form to display the recorded image data, as shown in Figure 13.

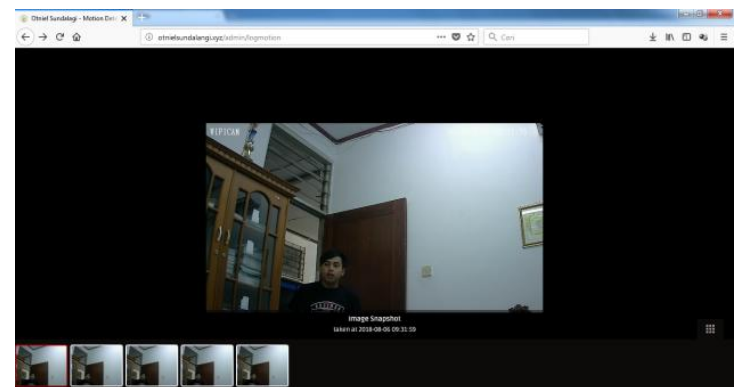

Fig13:Recorded display form via pressing the View button

From the results shown in Figure 13, it can be seen that the image data stored on the web server is 5 images according to the process of taking and sending images from the Esp32 controller.

If the process the user chooses is to print the recorded image data, then the thing to do is press the Download pdf button. When the Download pdf button is pressed, the system will direct the user to the storage section as shown in figure 14 .

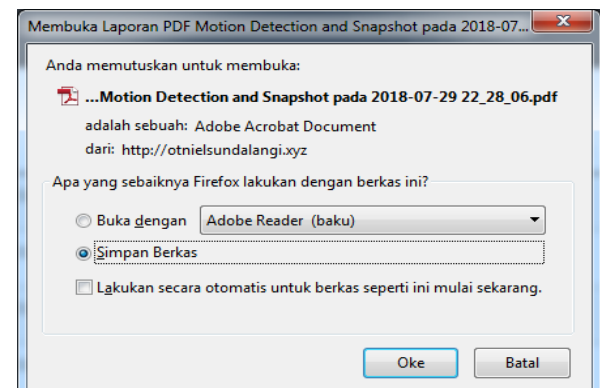

Fig14:The process of saving files when the Download pdf button is pressed

\section{CONCLUSIONS}

From the results of the research conducted, it can be concluded that the residential security system can carry out the security process, through the detection of human objects in the room through the PIR sensor, with sensor sensitivity ranging from 1 to 4 meters. When a human object is detected 
in the room, the system will activate the web cam to take pictures and send the image data to the web server via wifi communication. The image data taken and sent is limited to 5 data, in order to make the web cam work more efficiently and limit storage space. Image data stored on the web server can be viewed and downloaded in pdf format, for reporting to the authorities when there is an indication of theft.

\section{ACKNOWLEDGMENTS}

Many thanks to the organizers of the International Journal of Computer Application (IJCA) who have given the author the opportunity to publish this paper, as well as to the Manado State Polytechnic for facilitating the research process.

\section{REFERENCES}

[1] Eko Hari Atmoko, 2012, Membuat Sendiri CCTV Berkelas Enterprise Dengan Biaya Murah, ISBN: 978979-29-3255-3

[2] Eko Sakti Pramukantoro , 2019, Internet of Things dengan Python, ESP32, dan Raspberry Pi, ISBN: 978602-432-886-3 / 978-602-432-887-0(e)

[3] Sigit Wasista, Setyawardhana, Delima Ayu Saraswati, Eko Susanto, 2019, Aplikasi Internet Of Things (IoT) Dengan Arduino dan Android, Deepublish ORI.

[4] Rozali Toyib, Iwan Bustami, Dedy Abdullah, Onsardi Onsardi, 2019, Penggunaan Sensor Passive Infrared Receiver (Pir) Untuk Mendeteksi Gerak Berbasis Short Message Service Gateway, Jurnal Pseudocode
[5] Setyawan, P.S, 2017, Pengantar Teknologi Sensor, Penerbit UB Press, Malang.

[6] Jubille Enterprise, 2021, Pengantar Pemograman Android, PT. Elex Media Komputindo.

[7] Lawa, Z.C.J., Najoan, M.E.I., Lumenta, A.S.M., dan Tuegeh M., 2012, Prancangan Teknologi IP Camera di Jaringan Radio Wireless PT. PLN Wilayah Suluttenggo. Jurnal Teknik Elektro dan Komputer Unsrat Vol.1 No.3.

[8] Tampi, B.A.Y., Najoan, M.E.I., Sinsuw, A.A.E., dan Lumenta, A.S.M., 2013, Implementasi Routing pada IP Camera untuk Monitoring Ruang di Universitas Sam Ratulangi. Journal

[9] Ashardi, D., 2013, Rancang Bangun Aplikasi Pemantau Ruangan Melalui Kamera IP dengan Menggunakan Platform Android (Studi Kasus Laboratorium Teknik Informatika Universitas Tangjungpura. Jurnal Sistem dan Teknologi Informasi (JustIN) Vol.1 No.1

[10] Ruwaida, B., Minkkinen, T., 2013 Home Automation System A Cheap and Open Source Alternative to Control Household Appliances. Handbook.

[11] Suryansyah, 2015, Rancang Bangun Sistem Monitoring Keamanan Lingkungan Berbasis Wifi Menggunakan IP Camera. Jurnal Teknik Elektro Universitas Tanjungpura Vol.1 No. 1. 